receiver at the communication receiving station near San Francisco, California.

Following the publication of the technical paper referred to here, The Times of June 19 gave some details of an ionosonde developed by E.M.I.-Cossor Electronics Ltd., Halifax, Nova Scotia; and demonstrated recently to Commonwealth representatives, the Services and other organizations intorested in long-distance radio communication. The equipment was shown in operation between a sending station in Nova Scotia and the Post Office radio-receiving station at Cooling Marshes, near Rochester,
Kent. At the sender, the frequency was swopt in a series of 128 steps from 1.8 to $28 \cdot 8 \mathrm{Mc} / \mathrm{s}$, and the receiver was synchronized with the aid of standard time-signals. The received signals were displayed on a cathode-ray tube which, with the changing conditions in the ionosphere, indicated the most suitable frequency at any moment for transmission over this trans-Atlantic path. In addition to the direct assistance given to high-frequency communication, the ionosonde can be used for the scientific investigation of ionospheric conditions.

R. L. SMITH-Rose

\title{
NEW MATERIALS TESTING LABORATORY FOR THE CEMENT AND CONCRETE ASSOCIATION
}

$I^{N}$ $\mathrm{N}$ a recent issue of the Magazine of Concrete Research (15, No. 43; March 1963), J. D. McIntosh gives an interesting account of the imposing new laboratory erected for the Cement and Concrete Association at its research station at Woxham Springs, Stoke Poges, Slough, Bucks. The interest lies not so much in the fact that this is a much desired extension to the existing facilities at Wexham Springs, designed to re-house various departments hitherto operating in temporary accommodation, but in what may be termed the very 'tight' specification to which the building had to conform. The primary function of the new laboratory is research on the engineering properties of concrete and its constituent materials, including soil-cement; all necessary facilities for studying these problems and for structural model testing had to be provided and somewhat stringent measures had to bo taken to ensure that working conditions, for example, high degree of temperature control and correct relative humidity, in many of the rooms, were satisfied. In this, air-conditioning of much of the building plays an important part; it influenced the siting, planning and method of construction of this laboratory. "Particular problems included reducing nuisance from the dust and noise of many operations, preventing the spreading of shock and vibration to the rest of the structure, planning a convenient flow pattern for routine operations while allowing adequate versatility for other techniques, and filtering 'live' cement from liquid waste. Although all the desirable refinements were not included at the time of eroction, provision was made, where possible, for them to be incorporated later"
Thus the design of a materials-testing laboratory calls for solution of many problems not encountered in ordinary building, or at least much less critically. Every eventuality seems to have been foreseen in the present instance. Although ideally premises in which such fundamental research can be carried out should provide controlled conditions which can be taken for granted, any breakdown in vital equipment should be limited in its effect by appropriate planning in advance. While on one hand the layout should be designed in such a way that frequently recurrent operations can be reduced to a fool-proof routine, the building of this nature must be readily adaptable to now processes or testing procedures. It certainly seems from Mr. McIntosh's detailed description. of this new laboratory, coupled with the site-plan, floor plans and other illustrations in his paper, that the latest Wexham Springs project will eventually, if it has not already done so, fulfil the ideals which its sponsors and its architect had in mind. It certainly provides a most intriguing prototype for other buildings destined for similar purposes in the future and as it is intended that visitors will be encouraged to "see something of the laboratories without hindrance to the work in hand" (by provision of large windows between corridors and rooms and special circulation spaces), there will be no obstacle to architects and others concerned with design of special buildings for scientific work obtaining first-hand visible and highly valuable information on basic requirements.

H. B. Milner

\section{ISOSTATIC RECOVERY IN SCOTLAND}

\author{
BY D. F. W. BADEN-POWELL \\ Department of Geology and Mineralogy, University of Oxford
}

GOME years ago evidence was published for a corre$\checkmark$ spondence in height and fossil content of some British raised beaches and those of the Mediterranean area ${ }^{1,2}$. If the correlations based on that work are correct, there is obviously a contradiction with the theory that northern Britain has been rising during the Holocene as a result of isostatic recovery or that recent extensive tilting has occurred in England. In other words, if some British raised beaches which were originally horizontal are now tilted, their heights cannot be used as evidence of correlation with the Mediterrancan area. Recent work on the Pleistocene marine fauna of the Nar Valley Clay of western Norfolk and on an almost identical fauna from other parts of Britain has shed new light on recent crustal movements as a whole, and some widely held opinions on this subject must now be changed.

Jamieson ${ }^{3}$ seems to have been one of the first geologists to suggest that many Scottish raised beaches might be due to local uplift, and W. B. Wright ${ }^{4}$ later enlarged
Jamieson's ideas by assuming that most of the Scottish beds are late- or post-glacial and are not represented in the south of England, whereas the English fossil beaches were supposed to be much more ancient. This idea has bcen accepted so generally that it is often forgotten that it was challenged by Deperet ${ }^{5,6}$, who considered that some of the marine beds in the north can be correlated with those of southern England, and that it is not nocessary to invoke any form of crustal movement to explain their distribution. Another nearly related problem is that of the supposed recent tilting of the southern parts of Britain. The original levelling of England and Wales was done by the Ordnance Survey during $1840-60$, and when the re-levelling was carried out betwoen 1912 and 1921 , a discrepancy of nearly $2 \mathrm{ft}$. was found near Harwich and the Essex coast, as though there had been a submergence here since the original survey. Sir Charles Close ${ }^{7}$ thought this discrepancy was due to changes in sea-level caused by local meteorological effects and not to vertical crustal 